\title{
Characterizing social behavior, activity, and associations between cognition and behavior upon social grouping of weaned dairy calves
}

\author{
K. C. Horvath and E. K. Miller-Cushon ${ }^{1}$ \\ Department of Animal Sciences, University of Florida, Gainesville 32611
}

\begin{abstract}
Weaned dairy calves are commonly exposed to changing physical and social environments, and ability to adapt to novel management is likely to have performance and welfare implications. We characterized how behavioral responses of weaned heifer calves develop over time after introduction to a social group. Previously individually reared Holstein heifer calves (n $=15 ; 60 \pm 5 \mathrm{~d}$ of age; mean \pm standard deviation) were introduced in weekly cohorts $(5 \pm 3$ new calves/ wk) to an existing group on pasture $(8 \pm 2$ calves/ group). We measured activity and behavior on the day of initial introduction and after $1 \mathrm{wk}$, when calves were exposed to regrouping (addition of younger calves and removal of older calves from the pen). Upon introduction, calves had 2 to 3 times more visits to each region of the pasture; they also spent more time at the back of the pasture, closest to where they were introduced and furthest from the feeding area $(25.13$ vs. $9.63 \%$ of observation period, standard error $=5.04)$, compared with behavior after $1 \mathrm{wk}$. Calves also spent less time feeding (5.0 vs. $9.6 \%$ of observation period, standard error $=$ 0.82 ) and self-grooming (0.52 vs. $1.31 \%$ of observation period; standard error $=0.20)$ and more time within 1 to 3 body lengths of another calf (16.3 vs. $11.9 \%$ of observation period, standard error $=2.3)$ when initially grouped. We also explored whether behavioral responses to initial postweaning grouping might be associated with individual differences in behavioral flexibility. To evaluate this, we assessed cognition of individually housed calves $(\mathrm{n}=18)$ at 5 wk of age using a spatial discrimination task conducted in a T-maze to measure initial learning (ability to learn the location of a milk reward) and reversal learning (ability to relearn location of the milk reward when it was switched to opposite arm of the maze). Calves were categorized by reversal learning success (passed, $\mathrm{n}=6$, or failed, $\mathrm{n}=$
\end{abstract}

Received February 5, 2018.

Accepted April 6, 2018.

${ }^{1}$ Corresponding author: emillerc@ufl.edu
8). Calves that passed the reversal learning stage of the cognitive task spent less time at the back of the pen (9.3 vs. $27.4 \%$ of observation period, standard error $=$ 5.5) and tended to have lower latency to feed (121.8 vs. $306.2 \mathrm{~min}$; standard error $=96.4$ ) on the day of introduction compared with calves that failed reversal learning. Overall, we found that initial introduction to social grouping had a marked influence on behavior of weaned calves that decreased over time. Further, these results suggest that individual variability in cognitive ability may be predictive of behavioral responses and ability to adapt to a novel environment.

Key words: dairy calf, social behavior, feeding behavior, cognition

\section{INTRODUCTION}

After weaning, dairy calves are commonly exposed to novel social groups as well as a changing social environment, which is likely to influence their behavioral development and activity patterns. The majority of dairy calves in the United States are housed individually (63\%; USDA, 2016) and will be introduced to social groupings after weaning. Calves in seminatural conditions begin forming and maintaining groups with other calves around 6 wk of age (Rankine and Donaldson, 1968). However, calves housed individually have limited early opportunities for social interaction and bonding (Duve and Jensen, 2012). This may exert longer-term effects on the social behavior of weaned calves and their ability to integrate into a social group later in life (Broom and Leaver, 1978; Raussi et al., 2010). Detrimental effects of social isolation in early life on social development and later behavior have been widely explored in a range of species (e.g., primates, Harlow et al., 1965; and rodents, Gonzalez et al., 2001). Certain social behaviors, such as social grooming, are important for establishing and maintaining relationships between different members of a herd (Færevik et al., 2007). Calves reared individually with limited access to their neighbor exhibit less social sniffing and licking than pair-housed calves (Duve and Jensen, 2012), suggesting 
why individually housed calves are likely to experience social deficits.

Following initial introduction to a social group, most calves experience frequent regroupings as they grow and move through different developmental and management stages. Grouping unfamiliar animals may cause aggressive interactions and distress (Collis et al., 1979). However, familiarity and early social bonds seem to be long-lasting (Reinhardt et al., 1978) and may facilitate social integration into larger groups. Whereas grouping and regrouping is a normal part of dairy production, it can negatively affect performance and animal welfare, and the effects can last between 1 and 2 wk (Hasegawa et al., 1997; Kerr and Wood-Gush, 1987). Repeated regrouping can lead to increased agonistic interactions (Raussi et al., 2005), and weaned heifers have been observed increasing social licking and agonistic interactions in high stocking densities (Kerr and Wood-Gush, 1987). The ability to adapt to a novel environment and social instability may have important implications for performance and welfare, yet behavioral responses during this critical transition have not been well characterized.

Therefore, the first aim of our study was to characterize the development of activity patterns and social behavior upon postweaning grouping in calves reared individually. We hypothesized that, upon initial introduction to a social group after weaning, calves would exhibit more variation in behaviors throughout the day and less socially affiliative behaviors, such as selfgrooming, allogrooming, and maintaining a close social proximity to other calves, compared with behavior after a period of adaptation and subsequent regrouping.

As dairy cattle will encounter both changing physical environments and changing social environments, it is important for them to develop behavioral flexibility to better adapt to these changes. Understanding how early experiences can influence cognition in dairy calves is growing. Housing calves individually has been shown to impair behavioral flexibility and cognitive development (Meagher et al., 2015), and reversal learning in a spatial discrimination task is more difficult for individually housed calves compared with group-housed calves (Gaillard et al., 2014). Further, calves provided nutritional enrichment in the form of hay and a teat complete a reversal learning task more quickly (Horvath et al., 2017). Individual ability to adapt to environmental changes may depend on cognitive ability; however, implications of cognitive ability for behavioral outcomes relevant from a management and welfare standpoint have not been explored.

Therefore, our second aim was to evaluate associations between cognitive ability and behavioral responses upon grouping. We hypothesized that cognitive ability, as assessed before grouping using a spatial discrimination task, may be associated with an improved ability to adapt to a social group and novel environment after weaning. Specifically, we predicted that success in a reversal learning task may be associated with decreased latency to begin feeding and increased exploration.

\section{MATERIALS AND METHODS}

\section{Animals and Management}

Holstein heifer calves were enrolled at birth at the University of Florida Dairy Unit (Hague, FL). Calves were managed according to the standard operating procedures for this facility. They received $4 \mathrm{~L}$ of quality-controlled colostrum and were uniquely identified with radio frequency identification ear tags. Calves were housed in individual wire mesh pens $(0.9 \times 1.8$ $\mathrm{m}$; width $\times$ depth) that permitted visual and auditory, but not tactile, contact with other calves throughout the milk-feeding stage. Pens were bedded with sand that was replaced weekly. All calves received $8 \mathrm{~L} / \mathrm{d}$ (in 2 meals/d at 0600 and $1800 \mathrm{~h}$ ) of pasteurized waste milk mixed with a powdered enhancer (Pasteurized Milk Balancer Protein-Blend, Purina Animal Nutrition LLC, Shoreview, MN) for the first 2 wk of life, followed by an increase to $10 \mathrm{~L} / \mathrm{d}$ (in 3 meals/d at 0600, 1200, and $1800 \mathrm{~h}$ ) of milk from wk 3 until weaning at wk 6 of life. Calves had ad libitum access to calf starter (Ampli-Calf Starter 20 Warm Weather, Purina Animal Nutrition LLC) and water. Calves were weaned over 9 $\mathrm{d}$, beginning at wk 6 of life: milk allotment was reduced to $8 \mathrm{~L} / \mathrm{d}$ for $2 \mathrm{~d}$ (by removing the midday meal), then reduced to $4 \mathrm{~L} / \mathrm{d}$ for $7 \mathrm{~d}$ (by removing the evening meal) until calves were fully weaned at 8 wk of age. A veterinarian monitored the health of the calves weekly, and calves were healthy for the duration of the experiment.

Postweaning, all calves were moved into an open pasture $(15.2 \times 45.7 \mathrm{~m})$ in weekly cohorts $(5 \pm 3$ new calves/wk; mean $\pm \mathrm{SD}$ ) at $60 \pm 5 \mathrm{~d}$ of age. They were housed in groups of $8 \pm 2$ calves of $63 \pm 8 \mathrm{~d}$ of age for 2 wk. The group always consisted of newly introduced calves and calves introduced the previous week (study and nonstudy calves). On the first day of observation (d 1 of wk 1), calves were introduced to the pasture pen, and on the first day of the second week (d 1 of wk 2) calves experienced a partial social regrouping when previously added calves were removed and new calves were added to the pen. All study procedures were reviewed and approved by the University of Florida Animal Care and Use Committee. 


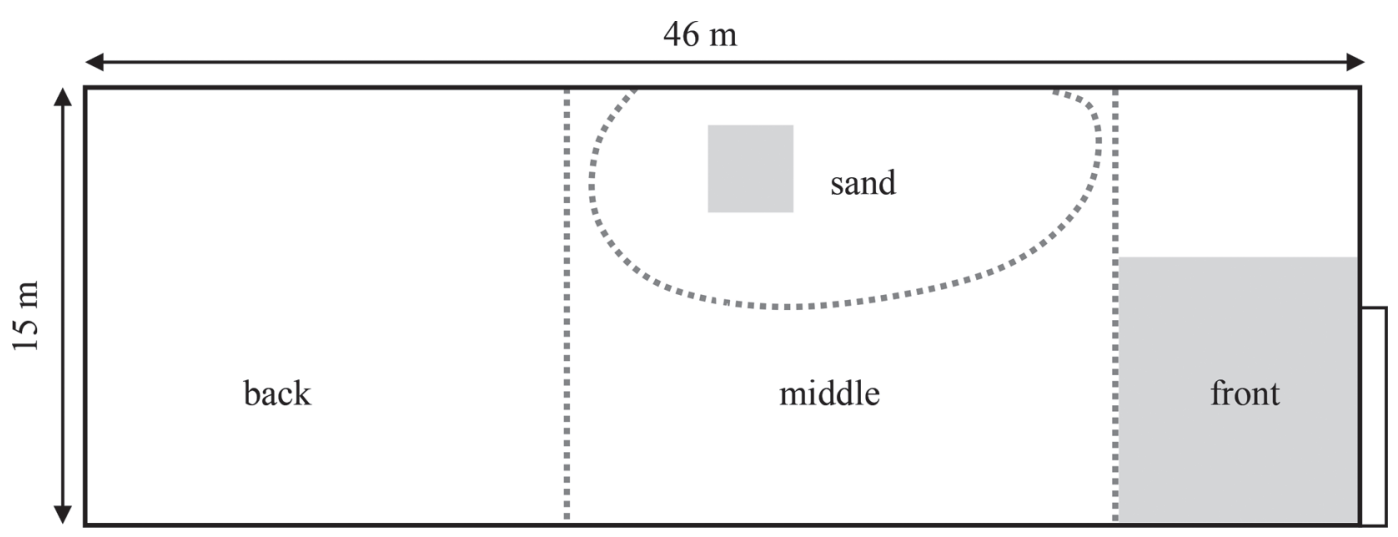

Figure 1. Diagram of the pasture pen that calves were moved to after weaning, indicating how regions of the pen were divided for behavioral observation (dashed gray lines). Light gray represents areas within regions that were shaded. The placement of the feed bunk (white rectangle) is shown at the front of the pen.

\section{Aim 1: Development of Behavior Following Social Grouping of Weaned Dairy Calves}

To characterize changes in behavior upon introduction to a social group, calves $(\mathrm{n}=15)$ were observed during a 2 -wk period encompassing the day of introduction to a pasture pen (d 1 of wk 1) and the first day of the following week, when calves experienced a partial social regrouping, with the next cohort of calves introduced to the group pen and older calves removed (d 1 of wk 2).

The behavior of all calves was recorded following introduction to the group pen after weaning using video from 2 wireless outdoor security cameras (FI9900P; Foscam, Shenzen, China) mounted in the pasture. One camera was focused on the feed bunk and the front of the pasture, and the second was focused to view the remaining part of the pasture (Figure 1). Behaviors were recorded continuously from video using Behavioral Observation Research Interactive Software (Friard and Gamba, 2016). We characterized the following behaviors: duration of time spent feeding (defined as head lowered in feed trough), duration of self-grooming (licking or mouth movement directed toward any part of own body or scratching with foot the back of head), duration of time allogrooming (licking or mouth movement directed toward any part of another calf's body or head), and duration of time spent in proximity to another calf (close social proximity, $<1$ body length away from nearest calf, or moderate social proximity, between 1 and 3 body lengths to nearest calf). Due to the large size of the pasture, we used 2 levels of social proximity to determine whether animals preferred to either be in close association with others, where active social behaviors such as allogrooming occur, or whether they were close enough to be considered within a vol- untary social proximity and part of a social group (e.g., approximately $10 \mathrm{~m}$; Wood-Gush et al., 1984) but too far to be actively performing social behaviors (moderate social proximity). The pasture size allowed calves to be easily beyond either social proximity distance, where they would be considered not part of a social group. To assess movement throughout the pasture pen, we subdivided the pasture into different regions (front, sand-bedded area, middle, back; Figure 1) and recorded the duration and frequency of visits to each region. These regions differed somewhat in size, but represented different functional areas that provided different resources. The feed bunk was located at the front of the pen along with a shaded cover, the sand-bedded area provided sand and a shade structure, the middle of the pen was largely dirt-covered and included the water trough, and the back of the pen was more isolated and grass-covered.

Feeding behavior was analyzed from the time when new calves entered the pen at $1200 \mathrm{~h}$ until midnight of the second day of both weeks (36-h observation period). All other behaviors were observed from entry into the pen at $1200 \mathrm{~h}$ until $1900 \mathrm{~h}$ on that day (7-h observation period), as all areas of the pen were not visible after sunset. A total of 4 observers were used to characterize these behaviors from video (interobserver reliability was calculated for video collection, with Pearson correlation coefficients exceeding $85 \%$ for all behaviors observed).

To assess general calf activity, standing time was monitored continuously upon entry into the pasture until the end of the experiment using electronic accelerometers (HOBO Pendant G data logger, Onset Computer Corp., Pocasset, MA) placed on the rear leg (as validated by Bonk et al., 2013). These data were used to calculate total daily standing time and hourly standing time. 


\section{Aim 2: Associations Between Cognition and Response to Social Grouping}

To assess the association between cognitive ability and adaptation to the group pen, cognition of calves $(\mathrm{n}=18)$ was assessed during wk 5 of life (before weaning) using a previously developed spatial discrimination task (Horvath et al., 2017). The test consisted of learning tasks in a T-maze (Figure 2). The maze was constructed using 24 panels $(0.61 \times 1.22 \mathrm{~m})$ of reconfigurable wire mesh pens (OxGord Inc., Los Angeles, $\mathrm{CA}$ ). The wire mesh panels were covered with corrugated plastic to create a visual barrier for the calves. Calves entered into the maze through the base of the $\mathrm{T}$ and exited through the arm containing the reward, which was allowed to open after the calves found and consumed their reward.

Each calf received a maximum of 6 sessions per day for $5 \mathrm{~d}$ or until criteria (moving directly to and begin consuming the reward in 3 consecutive sessions) was reached for all learning tasks. Each session had a maximum time of 3 min to complete the task. A reward of $0.2 \mathrm{~L}$ of milk was placed in one arm of the maze that was accessible through a teat, and reward location was balanced between each side to prevent an effect of laterality (Hosoi et al., 1995). The unrewarded side had no teat. Open containers of milk were placed outside each arm of the maze and out of sight of the calves to prevent calves from using olfactory cues to find the reward. Each calf was led through the maze on their first session and allowed to drink the milk reward. Calves received a maximum of 14 sessions or until criteria was met for initial learning. Calves unable to meet criteria were considered to not learn the task and were removed from further testing.

Once calves had met the learning criteria for the initial learning stage (moving directly to and begin con-

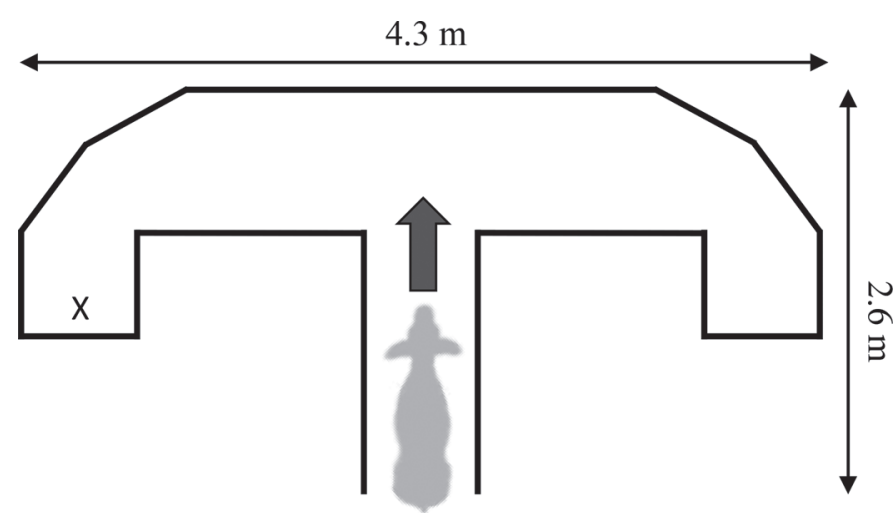

Figure 2. Diagram of the T-maze used to conduct the cognitive test. Milk reward was located in the area marked by an X, with initial side randomized between calves. suming the reward in 3 consecutive sessions), the location of the reward was changed to the opposite arm and reversal learning began. Calves received a maximum of 26 reversal learning sessions or until the learning criteria was met. Calves unable to meet this criterion were considered to have not learned the task.

Upon initial introduction to the pasture, we recorded behavioral responses from video, as described and defined above for aim 1: duration of time and frequency of visits to all regions of the pen, feeding time, latency to feed, duration of time at a close social proximity, duration of time at a moderate social proximity, duration of time spent allogrooming, duration of time spent self-grooming, duration of time standing, duration of standing bouts, and frequency of standing bouts.

\section{Statistical Analysis}

For aim 1, behavioral data were calculated as the percentage of time performing the behavior during the observation period (from introduction in wk 1 or regrouping in wk 2 at $1200 \mathrm{~h}$ until midnight the following day for feeding behaviors and until sunset at $1900 \mathrm{~h}$ for all other behaviors); these data were summarized by week (wk 1 and 2). Data were screened for normality using the UNIVARIATE procedure of SAS (version 9.4; SAS Institute Inc., Cary, NC). To meet assumptions of normality, we square root transformed the variables duration at the back of the pen, duration at the middle of the pen, frequency of visits to the front of the pen, frequency of visits to the middle of the pen, duration of time allogrooming, duration of time self-grooming, and duration of time at a moderate social proximity. These behavioral data were analyzed using the MIXED procedure of SAS in a general linear mixed model with week as a repeated measure. The model included the fixed effects of week and the random effect of calf within group. The duration of time in close social proximity could not be transformed to meet assumptions of normality and was analyzed using the Fisher-Pitman nonparametric permutation test (Berry et al., 2002) using the coin package in R (v. 1.2; Hothorn et al., 2006).

Standing and lying behavior were collected continuously throughout the 2-wk observation period and were summarized by day and week and analyzed in a double repeated measures model (week and day) using the MIXED procedure of SAS. Day was modeled with an unstructured variance-covariance structure and period was modeled as autoregressive order 1 . The model included the fixed effects of week and the random of effect of calf within group. For analysis of diurnal activity patterns, hourly data for $24 \mathrm{~h}$ following introduction in wk 1 and for $24 \mathrm{~h}$ following regrouping in wk 2 was analyzed in a double repeated measures model (hour 
Table 1. Duration and frequency of visits to each location ${ }^{1}$ in the pen following initial introduction to a social group after weaning (wk 1) and after regrouping 1 wk later (wk 2$)^{2}$

\begin{tabular}{|c|c|c|c|c|c|}
\hline \multirow[b]{2}{*}{ Item } & \multicolumn{2}{|c|}{ Week } & \multirow[b]{2}{*}{$\mathrm{SE}$} & \multirow[b]{2}{*}{$F_{1,14}$} & \multirow[b]{2}{*}{$P$-value } \\
\hline & 1 & 2 & & & \\
\hline \multicolumn{6}{|c|}{ Duration in region (\% of observation period $)^{3}$} \\
\hline Back & 25.13 & 9.63 & 5.04 & 4.18 & 0.046 \\
\hline Front & 35.71 & 34.96 & 5.85 & 0.01 & 0.92 \\
\hline Middle & 10.80 & 20.65 & 2.37 & 8.50 & 0.011 \\
\hline Sand & 31.84 & 34.64 & 6.89 & 0.69 & 0.76 \\
\hline \multicolumn{6}{|c|}{ Visit frequency (no./observation period) } \\
\hline Back & 8.32 & 2.78 & 0.71 & 35.38 & $<0.001$ \\
\hline Front & 8.50 & 4.97 & 0.61 & 22.87 & $<0.001$ \\
\hline Middle & 12.72 & 8.65 & 1.21 & 10.59 & 0.006 \\
\hline Sand & 12.65 & 4.85 & 1.06 & 57.45 & 0.10 \\
\hline
\end{tabular}

${ }^{1}$ Location of area in pen is visually represented in Figure 1.

${ }^{2}$ Data are summarized for $\mathrm{n}=15$ calves by observation period (between 6 and $7 \mathrm{~h}$ for each calf, depending on time of sunset) on the first day of wk 1 (when calves were first introduced to a new social group), and the first day of wk 2 (regrouping).

${ }^{3}$ For reference, $1 \%$ of observation period is approximately 4 min of time.

and week). Activity data were only analyzed for 12 calves due to logger recording faults and missing data. For data subject to a significant week $\times$ day interaction or day effect, the Tukey-Kramer adjustment was used in testing for appropriate pairwise differences (by day across weeks, or across days).

For aim 2, we analyzed associations between performance in the cognitive test and behavioral responses upon initial grouping. All data were summarized for the day of introduction into the group, for $24 \mathrm{~h}$ beginning at time of introduction (activity data from accelerometers and latency to feed) or from time of introduction until sunset at $1900 \mathrm{~h}$ (all other data). For this analysis, calves were categorized by performance in the cognitive task according to whether they had passed the reversal learning stage of the task $(\mathrm{n}=6$ passed; $\mathrm{n}=8$ failed), and we tested differences in behavioral responses between these classification groups using the MIXED procedure of SAS. In cases of unequal variances (latency to feed and standing bout duration), the Satterthwaite approximation was used to calculate degrees of freedom.

All values reported are least squares means. Significance was declared at $P<0.05$, and trends were reported if $0.05<P \leq 0.10$.

\section{RESULTS}

\section{Development of Behavior Following Social Grouping of Weaned Dairy Calves}

We observed differences between calf behavior when first introduced to a new social group (wk 1) and behavior 1 wk later, which corresponded with a social regrouping (wk 2). Calves spent a greater percentage of time in the back of the pen and spent less time in the middle of the pen on the day of introduction to the pen compared with 1 wk later (Table 1). The duration of time in the front of the pen and the sand-bedded area of the pen did not differ between weeks. Calves also had a greater frequency of visits to the back, front, and middle of the pasture pen immediately following grouping (Table 1).

Standing time was similar overall between weeks $\left(F_{1,11}\right.$ $=0.23, P=0.64)$, but differed by day $\left(F_{6.66}=3.78, P\right.$ $=0.0027)$. Calves stood for longer on the first day of the week, which corresponded with initial grouping in wk 1 and social regrouping in wk 2, compared with the second day of the week ( 81.0 min longer on $d 1$ vs. d 2 across weeks; $\mathrm{SE}=19.8 ; P=0.002$; Figure $3 \mathrm{a}$ ), and standing time tended to increase on the third day of the week (58.8 min longer on d 3 vs. d 2 across weeks; $\mathrm{SE}=19.8 ; P=0.062)$. Standing time across the rest of both weeks did not differ between consecutive days $(P>0.8)$. Standing bout frequency differed between weeks $\left(F_{1,11}=10.20 ; P=0.009\right)$, with calves having more frequent standing bouts in wk 1 , particularly at the beginning of the week (Figure $3 \mathrm{~b}$ ); standing bouts were consistently less frequent in wk 2. Corresponding to changes in frequency of standing bouts, we noted a tendency for standing bouts to be shorter in wk $1\left(F_{1,11}\right.$ $=3.35 ; P=0.09)$.

When comparing diurnal patterns of standing time on the day of introduction ( 1 of wk 1) and 1 wk later, on the day of social regrouping (d 1 of wk 2 ) we found a week by hour interaction $\left(F_{23.253}=3.45 ; P<\right.$ 0.001 ; Figure 4 ), with newly introduced calves standing longer in the hours immediately after introduction in wk 1 and having slightly different peaks in standing time throughout the rest of the day. 

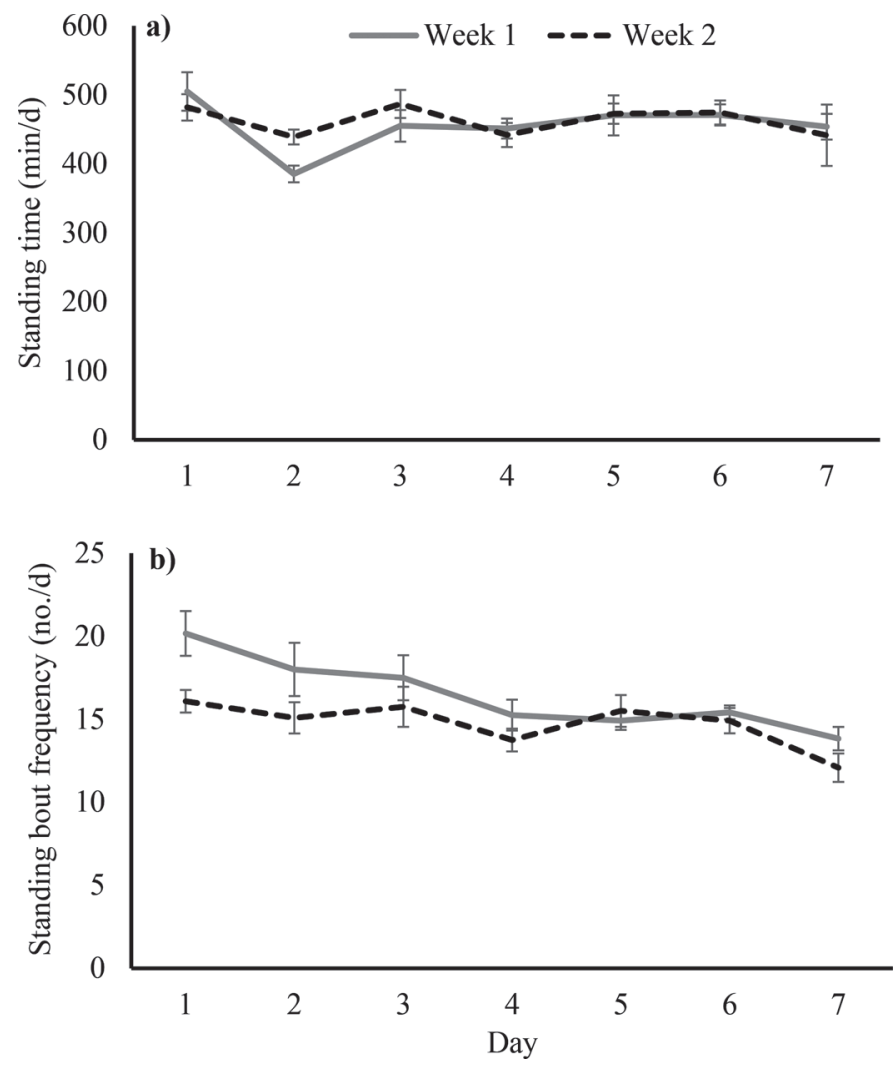

Figure 3. Total standing time (a) and frequency of standing bouts (b) over the $7 \mathrm{~d}$ following initial introduction to a group pen after weaning (wk 1) and after social regrouping within that pen (wk 2). Error bars represent SE of each data point.

Calves spent less of the observation period feeding during initial introduction to the group on the first day of wk 1 compared with 1 wk later (Table 2). The dura- tion of time in close social proximity to another calf ( $<1$ body length) was similar between weeks, but calves spent a greater percentage of time in a moderate social proximity (between 1 and 3 calf body lengths) to their nearest neighbor during the day of initial introduction. Calves spent a greater percentage of time allogrooming but less time self-grooming initially after grouping compared with after regrouping in wk 2 (Table 2).

\section{Associations Between Cognition and Response to Social Grouping}

Of all calves that were assessed in the cognitive test before weaning $(\mathrm{n}=18), 78 \%(\mathrm{n}=14)$ of the calves successfully completed the initial learning stage of the test and continued to reversal learning. Of the 14 calves that completed initial learning, $42 \%(\mathrm{n}=6)$ were able to successfully complete reversal learning. The number of sessions required to pass initial learning was not associated with success in reversal learning $(P=0.57)$. To evaluate associations between performance in the cognitive task and adaptation to the social environment, we compared behavioral responses upon initial grouping of those calves that were able to complete the reversal learning task with those that were not. Calves that passed the reversal learning task in the cognitive test spent less time in the back of the pen and spent a greater percentage of time in the front of the pen (Table 3) on the day of initial grouping. We also found a tendency for calves that passed reversal learning to spend more time in the middle of the pen, and there was no difference in the amount of time spent in the sand portion of the pen (Table 3). We observed no difference in the frequency of visits to different regions

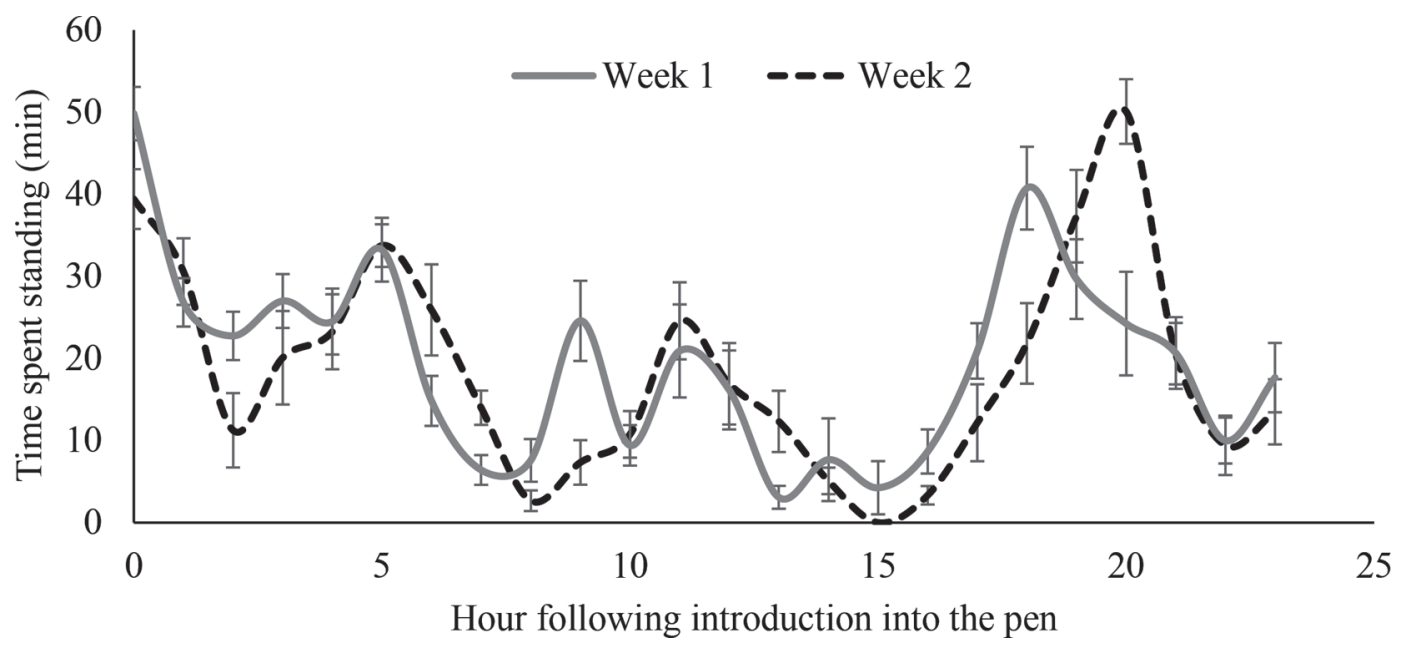

Figure 4. Diurnal pattern of standing time during the $24 \mathrm{~h}$ following initial introduction to a group pen after weaning (d 1 of wk 1$)$ and after social regrouping within that pen (d 1 of wk 2). Calves were introduced (h 1) at approximately 1200 h, with sunset around $1900 \mathrm{~h} \mathrm{(h} 7$ ) and sunrise around $0700 \mathrm{~h}(\mathrm{~h} \mathrm{20})$. Fresh feed was delivered at $0800 \mathrm{~h}$ (h 21). Milk was provided to adjacent preweaning calves at 0600 (h 19 ) and $1700 \mathrm{~h}(\mathrm{~h} 4)$. Error bars represent SE of each data point. 
Table 2. Social, feeding, and grooming behavior of calves (presented as a percentage of the observation period) on the day of introduction to a social group after weaning (wk 1) and after regrouping 1 wk later (wk 2) ${ }^{1}$

\begin{tabular}{|c|c|c|c|c|c|}
\hline \multirow{2}{*}{$\begin{array}{l}\text { Behavior } \\
(\% \text { of observation period })^{2}\end{array}$} & \multicolumn{2}{|c|}{ Week } & \multirow[b]{2}{*}{$\mathrm{SE}$} & \multirow[b]{2}{*}{$F_{1,14}$} & \multirow[b]{2}{*}{$P$-value } \\
\hline & 1 & 2 & & & \\
\hline Feeding time & 5.04 & 9.55 & 0.82 & 17.26 & 0.001 \\
\hline Self-grooming & 0.52 & 1.31 & 0.20 & 8.34 & 0.02 \\
\hline Allogrooming & 0.50 & 0.002 & 0.21 & 7.46 & 0.02 \\
\hline Close social proximity ${ }^{3,4}$ & 48.54 & 56.62 & 4.70 & - & 0.13 \\
\hline Moderate social proximity ${ }^{3}$ & 16.32 & 11.87 & 2.25 & 3.64 & 0.0077 \\
\hline
\end{tabular}

${ }^{1}$ Data are summarized for $\mathrm{n}=15$ calves by observation period (between 6 and $7 \mathrm{~h}$ for each calf, depending on time of sunset) on the first day of wk 1 (when calves were first introduced to a new social group), and the first day of wk 2 (regrouping).

${ }^{2}$ Behavioral data are summarized as a percentage of the observation period. For reference, $1 \%$ of observation period is approximately 4 min of time.

${ }^{3}$ Close social proximity was defined as $<1$ calf length to nearest neighbor. Moderate social proximity was defined as 1 to 3 calf lengths to nearest neighbor.

${ }^{4}$ Close social proximity was not normally distributed and was analyzed using the Fisher-Pitman permutation test.

of the pen. Calves that passed reversal learning spent less time standing and had shorter standing bout duration, but tended to have more frequent standing bouts (Table 3). Calves that passed reversal learning tended to begin feeding more quickly after introduction to the pen. Interestingly, 2 of the calves that did not pass reversal learning did not begin feeding until the following day ( $>11 \mathrm{~h}$ after introduction to the pen), whereas all other calves began feeding within approximately $4 \mathrm{~h}$. However, we found no association between performance in the cognitive task and the amount of time spent feeding. Calves that did not pass reversal learning tended to spend more time in close social proximity to another calf, and we noted no difference in the percentage of time spent at a moderate social proximity. We observed no associations between performance in the cognitive task and the amount of time spent self-grooming or allogrooming (Table 3).

\section{DISCUSSION}

Introduction to the group pen after weaning altered activity patterns of dairy calves, resulting in increased movement between locations in the pen and more frequent standing bouts compared with subsequent days. Consistent with other studies, calves had increased activity, with more movement between sections of the pen and more frequent standing bouts, upon entry into the group pasture with a new social group, followed by a reduction in activity after the first day (Veissier et al., 1994; De Paula Vieira et al., 2012). The pronounced behavioral response to initial grouping in the present study may be attributed to both introduction to social contact and the novelty of the environment. Whereas only social companions changed in wk 2 , all calves ex- perienced a change in space allotment in wk 1 (from 1.6 $\mathrm{m}^{2}$ in their individual hutches to roughly $140 \mathrm{~m}^{2} /$ calf in the group pasture). As such, behavioral changes in wk 1 may be attributed to general adaptation to a novel space. In contrast, the behavior of calves after $1 \mathrm{wk}$ was more stable compared with calves during the first day of introduction; however, we did see an increase in standing time at the beginning of both weeks, suggesting that calves were somewhat responsive to social regrouping alone. Similarly, Veissier et al. (2001) found that bull calves had diminished behavioral reactions after being exposed to several regrouping events and after the first 24-h period following regrouping.

It is also interesting to note that the diurnal pattern of standing activity changed after $1 \mathrm{wk}$ of social grouping on pasture (Figure 4). Calves spent more time standing immediately after initial grouping compared with the first day of the following week when social regrouping occurred. On the first day of introduction, calves had peaks in activity that corresponded roughly with previous milk delivery (afternoon milk was delivered at approximately $1700 \mathrm{~h}$, or h 4 postintroduction to the pen, and morning milk was delivered at 0600 h, or h 19 postintroduction, with the staff preparation typically beginning $1 \mathrm{~h}$ before). Calves on pasture were within range of visual and auditory cues associated with milk feeding (including vocalizations from preweaning calves, farm staff arrival), and they may have been more responsive to these cues during wk 1 , having been weaned more recently. Similarly, Miller-Cushon et al. (2013) described that recently weaned calves were more active at times corresponding to previous milk delivery, compared with behavior 7 wk after weaning. By the second week on pasture, calves in the present study were less responsive at times corresponding to 
Table 3. Associations between performance in a preweaning cognitive test and behavior during initial introduction to group housing (d 1 of wk 1); calves were categorized by success in the reversal learning stage of the test

\begin{tabular}{|c|c|c|c|c|c|}
\hline \multirow[b]{2}{*}{ Item } & \multicolumn{2}{|c|}{ Cognitive test outcome } & \multirow[b]{2}{*}{$\mathrm{SE}$} & \multirow[b]{2}{*}{$F_{1,12}$} & \multirow[b]{2}{*}{$P$-value } \\
\hline & Fail & Pass & & & \\
\hline \multicolumn{6}{|l|}{ Duration in region $(\% \text { observation period })^{1}$} \\
\hline Back & 27.43 & 9.33 & 5.49 & 6.21 & 0.028 \\
\hline Front & 25.01 & 42.59 & 5.69 & 5.44 & 0.038 \\
\hline Middle & 7.28 & 18.01 & 4.50 & 3.25 & 0.097 \\
\hline Sand & 39.85 & 29.74 & 8.05 & 0.90 & 0.361 \\
\hline \multicolumn{6}{|l|}{ Visit frequency (no./observation period) } \\
\hline Back & 9.00 & 7.83 & 1.38 & 0.41 & 0.53 \\
\hline Front & 9.75 & 9.66 & 1.48 & 0.001 & 0.97 \\
\hline Middle & 11.75 & 14.5 & 2.78 & 0.56 & 0.47 \\
\hline Sand & 14.13 & 12.5 & 1.72 & 0.51 & 0.49 \\
\hline \multicolumn{6}{|l|}{ Behavior $(\% \text { of observation period })^{1}$} \\
\hline Feeding time & 5.23 & 4.43 & 1.43 & 0.18 & 0.68 \\
\hline Self-grooming & 0.336 & 0.361 & 0.188 & 0.01 & 0.97 \\
\hline Allogrooming & 0.560 & 0.395 & 0.430 & 0.08 & 0.78 \\
\hline Close social proximity $^{2}$ & 54.52 & 39.39 & 6.39 & 3.20 & 0.099 \\
\hline Moderate social proximity $^{2}$ & 13.03 & 19.62 & 3.60 & 1.91 & 0.19 \\
\hline Latency to begin feeding ${ }^{3}$ (min) & 306.2 & 121.8 & 96.43 & 3.66 & 0.089 \\
\hline \multicolumn{6}{|l|}{ Activity data } \\
\hline Standing time $(\min )$ & 563.75 & 439.25 & 38.48 & 6.98 & 0.02 \\
\hline Standing duration ${ }^{3}(\mathrm{~min} /$ bout $)$ & 37.52 & 21.40 & 5.29 & 3.50 & 0.008 \\
\hline Standing bouts (no./observation period) & 16.00 & 19.75 & 1.54 & 3.96 & 0.07 \\
\hline \multicolumn{6}{|c|}{$\begin{array}{l}{ }^{1} \text { These data are summarized as a percentage of the observation period }(6-7 \mathrm{~h}) \text {. For reference, } 1 \% \text { of observatiol } \\
\text { period is approximately } 4 \mathrm{~min} \text { of time. }\end{array}$} \\
\hline \multicolumn{6}{|c|}{$\begin{array}{l}{ }^{2} \text { Close social proximity was defined as }<1 \text { calf length to nearest neighbor. Moderate social proximity was de } \\
\text { fined as } 1-3 \text { calf lengths to nearest neighbor. }\end{array}$} \\
\hline $\begin{array}{l}{ }^{3} \text { Degrees of freedom calculated using Satt } \\
\text { denominator degrees of freedom to } \sim 8 \text {. }\end{array}$ & approxim & due to u & [ual grou] & & s, reducin \\
\hline
\end{tabular}

previous milk delivery and had a greater peak in activity corresponding to delivery of fresh freed $(0800 \mathrm{~h}$, or h 21 postintroduction).

We observed slight changes in social behavior during adaptation to the group pen. Calves spent a greater percentage of the observation period in a moderate social proximity (between 1 and 3 calf body lengths) from the nearest social partner during the day of introduction into the group compared with regrouping in the following week. Kondo et al. (1984) found that previously individually housed calves will decrease the mean distance from their nearest neighbor over the course of several days after introduction into group housing. We saw a numerical increase in time spent in a close social proximity ( $<1$ body length) between weeks, but did not find a statistically significant difference. Decreasing social proximity distance is considered necessary for social group formation; however, large space allotments and small group sizes have been shown to increase the distance between nearest neighbors in calves (Kondo et al., 1989), which may explain why we did not see substantial changes in social proximity distance over time.

Both self-grooming and allogrooming provide a benefit to calves by providing a hygienic maintenance of their body (Kohari et al., 2009; Rich, 1973). Allogrooming is additionally important for maintaining bonds between individual cattle in a group (Færevik et al., 2007) and has the potential to cause a calming effect by reducing the heart rate of the receivers (Laister et al., 2011). Although we predicted that we would see an increase in allogrooming over time as calves gained social experience, we observed a decrease in allogrooming. Similarly, Færevik et al. (2007) found that social grooming did not increase over time when group size was less than 16 calves. We did, however, see an increase in the amount of self-grooming performed between weeks. Other studies have reported no effects of housing factors, such as social housing (Chua et al., 2002), on the performance of self-grooming. We speculate that reduced self-grooming upon initial grouping was related to the greater activity and exploratory behavior we observed (i.e., movement between regions of the pen).

We found that calves spent less time feeding following initial introduction into the group compared with social regrouping in the following week. Whereas minimal decreases in feeding after regrouping have been noted in lactating dairy cows (von Keyserlingk et al., 2008), the present results suggest that the combination of introduction to a novel environment and first exposure to a social group is quite disruptive to behavior of 
recently weaned calves. Importantly, feeding management changed upon introduction to the postweaning group; whereas calves were provided starter in a bucket in their pen before weaning, starter in the group pen was provided via a feed bunk. Although we did not measure growth of calves during our study, Kondo et al. (1984) described a decrease in daily gain in response to grouping, which could suggest that those calves also experienced decreased feeding time and feed intake. Effects of social disruption on feeding behavior may vary by age. Weaned heifers exposed to repeated regrouping have been reported to return to eat more quickly during an open-field test than heifers that have not been regrouped (Raussi et al., 2006). In contrast, Boissy et al. (2001) described that weekly regrouping in pairhoused calves increased the latency to return to feeding following an umbrella test compared with stable social groupings, potentially due to increased fear (Boissy et al., 2001). Calves in the present study were of similar age, suggesting that changing physical and social environments may affect younger calves more than heifers that are only a few months older.

Behavioral flexibility is an important measure of the ability of an individual to interact with environmental stimuli and adjust behavior in response to these cues (Coppens et al., 2010). Maze tests are a common method for measuring behavioral flexibility and determining fixed behavioral strategies (e.g., active vs. passive coping) that animals take when encountering environmental changes (Benus et al., 1990; Bolhuis et al., 2004; Coppens et al., 2010). Behavioral responses upon introduction to a group and the capacity for behavioral flexibility assessed through the ability to perform reversal learning in a maze might be predictive of later behavior strategies. Interestingly, we observed associations between performance in the reversal learning task in the cognitive test and behavioral responses upon introduction to the group. In general, the behavior of calves that passed reversal learning may suggest that they adapted more quickly to the pen upon introduction. Calves spent less time at the back of the pen, which is where they first entered, and were more likely to be at the front of the pen, where the feedbunk was located, and tended to have a shorter latency to begin feeding. Although calves allocated their time differently between regions of the pen, we found no association between performance in the reversal learning task and the frequency of visits to each location of the pen. This is similar to behavioral differences observed between individually and group-housed calves in an open-field test with a novel calf present. Jensen et al. (1997) reported calves moved between sections of an open field test at a similar rate, but that group-housed calves spent less time in the central area of the field test, suggesting they were less fearful. Additionally, we observed that calves that did not pass reversal learning spent more time standing and tended to have fewer lying bouts. These behavioral differences in calves that did not pass reversal learning are generally similar to changes in activity described at regrouping; for example, von Keyserlingk et al. (2008) describe reduced lying time and lying bout frequency in cows after regrouping. Overall, differences in the distribution of time between regions of the pen, activity, and tendency for longer latencies to begin feeding suggest that calves that did not pass reversal learning may have a heightened response to initial grouping, including increased fear responses to the novel environment. Further, calves that did not pass the reversal learning task tended to spend more time within 1 body length of another calf, suggesting that they may have preferred to be in close contact with another calf, which has been shown to be a strategy to reduce reactivity to potential fear-eliciting responses (Boissy and Le Neindre, 1990). To our knowledge, this is the first research to date to explore links between individual variability in response to a cognitive test and behavioral responses in cattle. These results suggest that individual variability in cognitive ability may be predictive of behavioral outcomes, and we encourage further research with a larger population of animals to explore implications of cognitive ability for cattle performance and welfare.

\section{ACKNOWLEDGMENTS}

We thank the staff and students at the University of Florida Dairy Unit. In particular, we thank Catherine Hixson, Rachel Brick, Amber DeWitt, James Gross, Mackenzie Holmes, Katie Kleppinger, Taylor Pollak, Halie Weber, and Codie Whitehead of the Department of Animal Sciences, University of Florida, for their technical assistance. KH was supported by a Matching Assistantship through the Department of Animal Sciences, University of Florida.

\section{REFERENCES}

Benus, R., S. Den Daas, J. M. Koolhaas, and G. A. Van Oortmerssen. 1990. Routine formation and flexibility in social and non-social behaviour of aggressive and non-aggressive male mice. Behaviour 112:176-193.

Berry, K. J., P. W. Mielke, and H. W. Mielke. 2002. The FisherPitman permutation test: An attractive alternative to the $\mathrm{F}$ test. Psychol. Rep. 90:495-502.

Boissy, A., and P. Le Neindre. 1990. Social influences on the reactivity of heifers - implications for learning-abilities in operant-conditioning. Appl. Anim. Behav. Sci. 25:149-165.

Boissy, A., I. Veissier, and S. Roussel. 2001. Behavioral reactivity affected by chronic stress: an experimental approach in calves subjected to environmental instability. Anim. Welf. 10:175-185. 
Bolhuis, J. E., W. G. P. Schouten, J. A. D. Leeuw, J. W. Schrama, and V. M. Wiegant. 2004. Individual coping characteristics, rearing conditions and behavioural flexibility in pigs. Behav. Brain Res. 152:351-360.

Bonk, S., O. Burfeind, V. S. Suthar, and W. Heuwieser. 2013. Technical note: Evaluation of data loggers for measuring lying behavior in dairy calves. J. Dairy Sci. 96:3265-3271.

Broom, D. M., and J. D. Leaver. 1978. Effects of group-rearing or partial isolation on later social behavior of calves. Anim. Behav. 26:1255-1263.

Chua, B., E. Coenen, D. J. Van, and D. M. Weary. 2002. Effects of pair versus individual housing on the behavior and performance of dairy calves. J. Dairy Sci. 85:360-364.

Collis, K. A., S. J. Kay, A. J. Grant, and A. J. Quick. 1979. The effect on social organization and milk production of minor group alterations in dairy cattle. Appl. Anim. Ethol. 5:103-111.

Coppens, C. M., S. F. de Boer, and J. M. Koolhaas. 2010. Coping styles and behavioural flexibility: Towards underlying mechanisms. Philos. Trans. R. Soc. B Biol. Sci. 365:4021-4028.

De Paula Vieira, A., A. M. de Passillé, and D. M. Weary. 2012. Effects of the early social environment on behavioral responses of dairy calves to novel events. J. Dairy Sci. 95:5149-5155.

Duve, L. R., and M. B. Jensen. 2012. Social behavior of young dairy calves housed with limited or full social contact with a peer. J. Dairy Sci. 95:5936-5945.

Færevik, G., I. L. Andersen, M. B. Jensen, and K. E. Bøe. 2007. Increased group size reduces conflicts and strengthens the preference for familiar group mates after regrouping of weaned dairy calves (Bos taurus). Appl. Anim. Behav. Sci. 108:215-228.

Friard, O., and M. Gamba. 2016. BORIS: A free, versatile open-source event-logging software for video/audio coding and live observations. Methods Ecol. Evol. 7:1325-1330.

Gaillard, C., R. K. Meagher, M. A. G. von Keyserlingk, and D. M. Weary. 2014. Social housing improves dairy calves' performance in two cognitive tests. PLoS One 9:e90205.

Gonzalez, A., V. Lovic, G. R. Ward, P. E. Wainwright, and A. S. Fleming. 2001. Intergenerational effects of complete maternal deprivation and replacement stimulation on maternal behavior and emotionality in female rats. Dev. Psychobiol. 38:11-32.

Harlow, H. F., R. O. Dodsworth, and M. K. Harlow. 1965. Total social isolation in monkeys. Proc. Natl. Acad. Sci. USA 54:90-97.

Hasegawa, N., A. Nishiwaki, K. Sugawara, and I. Iwao. 1997. The effects of social exchange between two groups of lactating primiparous heifers on milk production, dominance order, behavior and adrenocortical response. Appl. Anim. Behav. Sci. 51:15-27.

Horvath, K., M. Fernandez, and E. K. Miller-Cushon. 2017. The effect of feeding enrichment in the milk-feeding stage on the cognition of dairy calves in a T-maze. Appl. Anim. Behav. Sci. 187:8-14.

Hosoi, E., L. Rittenhouse, D. M. Swift, and R. W. Richards. 1995. Foraging strategies of cattle in a Y-maze: influence of food availability. Appl. Anim. Behav. Sci. 43:189-196.

Hothorn, T., K. Hornik, M. A. van de Wiel, H. Winell, and A. Zeileis. 2006. Package 'coin': Conditional inference procedures in a permutation test framework. v. 1.2-2. Accessed Nov. 28, 2017. http:// CRAN.R-project.org $/$ package $=$ coin .

Jensen, M. B., K. S. Vestergaard, C. C. Krohn, and L. Munksgaard. 1997. Effect of single versus group housing and space allowance on responses of calves during open-field tests. Appl. Anim. Behav. Sci. 54:109-121.
Kerr, S. G. C., and D. G. M. Wood-Gush. 1987. The development of behaviour patterns and temperament in dairy heifers. Behav. Processes 15:1-16.

Kohari, D., S. Sato, and Y. Nakai. 2009. Does the maternal grooming of cattle clean bacteria from the coat of calves? Behav. Processes 80:202-204.

Kondo, S., N. Kawakami, H. Kohama, and S. Nishino. 1984. Changes in activity, spatial pattern and social behavior in calves after grouping. Appl. Anim. Ethol. 11:217-228.

Kondo, S., J. Sekine, M. Okubo, and Y. Asahida. 1989. The effect of group size and space allowance on the agonistic and spacing behavior of cattle. Appl. Anim. Behav. Sci. 24:127-135.

Laister, S., B. Stockinger, A. M. Regner, K. Zenger, U. Knierim, and C. Winckler. 2011. Social licking in dairy cattle -Effects on heart rate in performers and receivers. Appl. Anim. Behav. Sci. 130:8190 .

Meagher, R. K., R. R. Daros, J. H. C. Costa, M. A. G. von Keyserlingk, M. J. Hötzel, and D. M. Weary. 2015. Effects of degree and timing of social housing on reversal learning and response to novel objects in dairy calves. PLoS One 10:e0132828.

Miller-Cushon, E. K., R. Bergeron, K. E. Leslie, and T. J. DeVries. 2013. Effect of milk feeding level on development of feeding behavior in dairy calves. J. Dairy Sci. 96:551-564.

Rankine, G., and L. E. Donaldson. 1968. Animal behaviour and calf mortalities in a North Queensland breeding herd. Proc. Aust. Soc. Anim. Prod. 7:138-143.

Raussi, S., A. Boissy, S. Andanson, J. Kaihilahti, P. Pradel, and I. Veissier. 2006. Repeated regrouping of pair-housed heifers around puberty affects their behavioural and HPA axis reactivities. Anim. Res. 55:131-144.

Raussi, S., A. Boissy, E. Delval, P. Pradel, J. Kaihilahti, and I. Veissier. 2005. Does repeated regrouping alter the social behaviour of heifers? Appl. Anim. Behav. Sci. 93:1-12.

Raussi, S., S. Niskanen, J. Siivonen, L. Hänninen, H. Hepola, L. Jauhiainen, and I. Veissier. 2010. The formation of preferential relationships at early age in cattle. Behav. Processes 84:726-731.

Reinhardt, V., F. M. Mutiso, and A. Reinhardt. 1978. Social behaviour and social relationships between female and male prepubertal bovine calves (Bos indicus). Appl. Anim. Ethol. 4:43-54.

Rich, G. B. 1973. Grooming and yarding of spring-born calves prevent paralysis caused by the Rocky Mountain wood tick. Can. J. Anim. Sci. 53:377-378.

USDA. 2016. Dairy cattle management practices in the United States, 2014. Natl. Anim. Heal. Monit. Syst. 268. Accessed Apr. 3, 2017. http://www.aphis.usda.gov/nahms.

Veissier, I., A. Boissy, A. M. de Passillé, J. Rushen, C. G. Van Reenen, S. Roussel, S. Andanson, and P. Pradel. 2001. Calves' responses to repeated social regrouping and relocation. J. Anim. Sci. 79:2580-2593.

Veissier, I., V. Gesmier, P. Le Neindre, and J. Y. Gautier. 1994. The effects of rearing in individual crates on subsequent social behaviour of veal calves. Appl. Anim. Behav. Sci. 41:199-210.

von Keyserlingk, M. A. G., D. Olenick, and D. M. Weary. 2008. Acute behavioral effects of regrouping dairy cows. J. Dairy Sci. 91:10111016

Wood-Gush, D. G. M., K. Hunt, K. Carson, and S. G. C. Dennison. 1984. The early behavior of suckler calves in the field. Biology of Behavior 9:295-306. 